One possible explanation for trainees' high expectation is the widespread knowledge of the role and function of CAPSAC and of the higher training requirements. It was disappointing however, that given the College's encouragement of junior doctor representation at all levels, so few trainees were aware of their representatives on the Collegiate Trainees Committee.

In conclusion, it would seem that today's trainees are more eclectic, more research orientated and more community based. They are willing to see a larger range of clinical problems but lack training opportunities in some of these areas. They do not yet feel adequately supervised, although this has improved over nine years. We suggest that another similar survey is carried out in about five years to indicate changes over that period. We also hope that a parallel survey of the trainers for each scheme will be carried out in the near future.

\section{Acknowledgements}

The authors would like to thank Miss Suzanna Goodwyn for ensuring that all trainees received the questionnaire and Dr Peter Hill for commenting on an earlier draft. Dr Garralda kindly supplied us with an original copy of the 1979 questionnaire.

Further tabulated results are available from Dr Bools.

\section{References}

BLACK, D. (1989) Consultant manpower in child psychiatry. Psychiatric Bulletin, 13, 32-55.

Collegiate Trainees' Commitree (1987) Part-time training in psychiatry. A brief guide to the options available. Bullet in of the Royal College of Psychiatrists, 11, 137-142.

DHSS (1986) Hospital Medical Staffing-Achieving a Balance. London: DHSS.

GATH, A. (1988) Part-time senior registrar training in child and adolescent psychiatry. Bulletin of the Royal College of Psychiatrists, 12, 368-370.

Garralda, M. E., Wieselberg, M. \& Mrazek, D. A. (1983) A survey of training in child and adolescent psychiatry. British Journal of Psychiatry, 143, 498-504.

JOINT COMmITteE ON Higher PSYChIATRIC TRAINING (1987) Handbook. London: Royal College of Psychiatrists.

JoINT WorkING PARTY (1989) the training required to provide a psychiatric service for children and adolescents with mental handicaps. Psychiatric Bulletin, 13, 326-328.

\title{
Child and adolescent psychiatry training schemes: recent developments
}

\author{
Peter Reder, Consultant; and Clare Lucey, Senior Registrar, Department of Child \& \\ Family Psychiatry, Charing Cross Hospital, 2 Wolverton Gardens, London W6
}

Child and adolescent psychiatry training has progressed considerably in recent years. Additional training posts have been created, as well as senior academic appointments, and some pre-existing rotations have coalesced, allowing innovative schemes of high quality to evolve. CAPSAC (Child and Adolescent Psychiatry Specialist Advisory SubCommittee) has continued to oversee established standards and encourage these changes.

We were interested to review the present position in order to discover the number of schemes and training posts in existence and the developments that have occurred. This report is based on a questionnaire sent to all post-graduate tutors in child and adolescent psychiatry listed by CAPSAC. We asked each tutor to record the name of the scheme, the number of senior registrars, lecturers, and part-time senior registrars currently training, how long they spend in each leg of the rotation, and how many consultants are available to offer training placements.

We also asked more open-ended questions about specific aspects of the schemes, including experience of child guidance, in-patients, day-patients, mental handicap, paediatric liaison, management skills, the psychological therapies, and the organisation of research and academic components. Finally, we asked the tutors to comment on what they considered the special features of their scheme, significant changes that have occurred in the past two years, and changes they anticipated over the next two years.

All tutors responded, and we are very grateful to them for their co-operation. 
TABLE I

Child and adolescent psychiatry training schemes

\begin{tabular}{|c|c|c|c|c|c|}
\hline \multirow[b]{2}{*}{ Name of training scheme } & \multicolumn{3}{|c|}{ Number of trainees } & \multirow{2}{*}{$\begin{array}{c}\text { Number of } \\
\text { months spent } \\
\text { in each leg }\end{array}$} & \multirow{2}{*}{$\begin{array}{l}\text { Number of } \\
\text { consultants } \\
\text { involved }\end{array}$} \\
\hline & Senior reg. & Lecturers & Part-time & & \\
\hline Aberdeen & 1 & & & $6-12$ & 6 \\
\hline Bethlem Royal \& Maudsley SHA & 6 & 1 & 5 & 15 & 12 \\
\hline Bloomsbury & 2 & & & 12 & 4 \\
\hline Bristol & 4 & & 1 & 12 & 6 \\
\hline East Anglian Regional Rotation & 4 & 1 & 1 & 12 & 12 \\
\hline Eastern Health Board, Dublin & 1 & 2 & & $6-12$ & 5 \\
\hline Edinburgh & 2 & & 3 & $12-18$ & 6 \\
\hline Exeter & $i$ & & & 12 & 4 \\
\hline Galway & 2 & & & 18 & 2 \\
\hline Guy's/St Thomas'/Lewisham (Chatham) & 4 & 1 & & 15 & 7 \\
\hline Hospital for Sick Children, London & 4 & & & 12 & 7 \\
\hline King's College Hospital & 1 & & & $15-18$ & 3 \\
\hline London Hospital & 3 & & 1 & 16 & 6 \\
\hline Mater Misericordiae, Dublin & 1 & & & $6-12$ & 4 \\
\hline Mersey & 4 & 1 & 1 & 12 & 8 \\
\hline North Eastern Rotational & 6 & 1 & 1 & 12 & 12 \\
\hline Northern Ireland & 1 & & $i$ & $6-12$ & 3 \\
\hline North West Regional & 10 & & & $6-18$ & 12 \\
\hline North West Thames & 5 & 1 & & 16 & 11 \\
\hline Oxford Regional & 5 & $i$ & 3 & 16 & 12 \\
\hline St George's & 5 & 1 & 2 & 15 & 17 \\
\hline St John of God, Dublin & 2 & & & 24 & 7 \\
\hline Southampton/Portsmouth & 4 & & & 24 & 9 \\
\hline South Wales Rotational & 6 & & 1 & 15 & 15 \\
\hline Tavistock Clinic Conjoint & 9 & 1 & & $12-24$ & 19 \\
\hline Tayside & 1 & & 2 & $12-14$ & 4 \\
\hline Trent (Leicestershire) & 3 & 2 & 1 & 12 & 8 \\
\hline Trent (Nottingham/Derby) & 2 & & & 12 & 6 \\
\hline Trent (Sheffield) & 2 & & & 12 & 4 \\
\hline West Midlands Rotational & 9 & & 1 & $12-18$ & 22 \\
\hline West of Scotland & 3 & 1 & & 12 & 18 \\
\hline Yorkshire Regional & 6 & & 2 & 12 & 9 \\
\hline
\end{tabular}

\section{The schemes}

CAPSAC currently recognises 32 separate schemes in England, Wales, Scotland and Ireland, listed in Table I.

Six of these schemes already co-operate closely together and three more anticipate some integration in the near future. For example, links have recently developed between the three elements of the Trent rotation, and Aberdeen have arranged secondment of their senior registrar to a neighbouring centre. The King's College Hospital scheme expects a closer association with the Bethlem Royal and Maudsley SHA, the Bloomsbury training may integrate with others in the North East Thames Region, and a national rotation is anticipated in Ireland.

Co-operation particularly occurs around academic programmes, which bring senior registrars together from disparate bases, and 11 schemes currently link up with others for the formal academic teaching.
Some training programmes are already well established, but we were impressed by the enthusiastic comments from tutors of rotations which had recently come together or expanded through the creation of new training posts. It seems that once a critical number of trainees and trainers is achieved, significantly greater variety is possible, allowing the whole to become more than a sum of its parts.

Geographical distance between centres was seen by some tutors as a positive benefit, permitting senior registrars to gain experience of problems in both urban and rural communities.

The length of time trainees spend in each leg of the rotations ranges from six months to two years. In 16 schemes placements are for one year or less, and we wonder whether there is a trend to reduce the duration of training legs as a means of ensuring diversity of experience. Certainly, breadth of experience was emphasised as an important feature of their scheme by 
23 tutors but, we noted, depth of experience was rarely highlighted as a special strength.

\section{Trainees}

At the time of our study (February 1990) there were 158 training posts in existence, comprising 119 senior registrars, 14 lecturers, and 25 part-time senior registrars (see Table I). Eight tutors reported an increase in the number of training posts over the last two years, while ten anticipate an increase in the near future. However, by contrast, three posts have been frozen or lost.

Two tutors commented on the benefits to the scheme of trainee peer group relationships when programmes link together.

\section{Special components}

We presumed that the core experience in all schemes would be general, out-patient child and adolescent psychiatry. We therefore asked for more information about additional, special components.

As would be expected, all schemes include specific in-patient, paediatric liaison, forensic, formal academic teaching, and research experiences. The majority (31) also offer involvement in a day-unit and exposure to child mental handicap (29).

Child guidance Child guidance experience is clearly present in only 20 of the 32 schemes. Some tutors in Scotland and Ireland reported that the child guidance concept does not exist as such in these countries, but there are still six of the 23 rotations in England and Wales in which trainees do not work in a child guidance unit. This may well be a developing trend, since one tutor declared that the child guidance service had collapsed locally, and another reported the dissolution of their local child guidance facilities with only liaison remaining.

Therapies There was wide variation in the teaching of psychological therapies. Sixteen schemes provide a formal course in family therapy, 12 in dynamic psychotherapy, but only seven in behavioural techniques. Five schemes offer formal courses in all three modalities. Informal training, through expert supervision coupled with theoretical input on the academic programme, appears to be available in the majority of other schemes, while some also encourage trainees to attend external courses. Supervision of group therapy was specified by three tutors, and of hypnosis by one.

\section{Special developments}

Forensic All schemes offer some forensic experience as part of the general clinical work but, in addition, eight rotations have at least one consultant child psychiatrist with a special forensic interest able to offer trainees placements in special units or in child sexual abuse teams. Two further schemes are negotiating links with adult forensic psychiatrists, while one tutor has created a lecturer post specialising in forensic child and adolescent psychiatry.

Mental handicap Experience of mental handicap ranges from occasional attendance at special schools or district handicap team meetings to intensive input from child psychiatrists taking a particular interest in developmental disorders. The available experience in mental handicap is considered a special feature of six schemes. This includes exposure to developmental paediatrics, communication disorders and neuro-psychiatry, and one scheme devotes a fulltime leg to the psychiatry of developmental disability.

A service arrangement with significant training implications was reported from two centres, where mental handicap services are integrated with the general child mental health provision.

Management skills While the majority of schemes (29) include some training in management, this ranged from a basic "being a member of a committee" or "being responsible for some tasks" through to running a unit. Some innovative developments were reported, including an "apprenticeship" model in which trainees learn alongside consultants for a period of time. Sixteen schemes offer trainees special management courses, and a further two include seminars on management in their academic programme.

Academic Many tutors emphasised the high standards they aim for, and eight named this as a special feature. Six tutors reported increased academic influences over the last two years through the appointment of professors, senior lecturers, or lecturers, a high profile of research, or new university links. A further six expected such developments. Where it is occurring, the greater influence of an academic department seems to be highly valued, and tutors commented how research and teaching components of their schemes had benefited. For example, one scheme has introduced written, personalised training targets for each senior registrar and tuition in the skills of teaching.

\section{Comments}

Many stimulating developments have occurred in the training of child and adolescent psychiatrists, with increasing facilities to teach developmental paediatrics, forensic child psychiatry, research, management skills and the psychological therapies. Child guidance experience may be declining. There appear to be advantages in links between neighbouring schemes and with academic departments.

Finally, the unique qualities of respective rotations seem especially significant, and we would suggest that differences between the schemes must be at least as important as their similarities. 